\title{
Langmuir monolayer study of phospholipid DPPC on the titanium dioxide-chitosan-hyaluronic acid subphases
}

\author{
Agata Ładniak ${ }^{1}$ (D) $\cdot$ Małgorzata Jurak $^{1}$ (D) Agnieszka Ewa Wiącek $^{1}$ (D)
}

Received: 3 December 2018 / Revised: 6 February 2019 / Accepted: 7 February 2019 / Published online: 19 February 2019

(c) The Author(s) 2019

\begin{abstract}
The studies of model biological membranes consisted of phospholipid 1,2-dipalmitoyl-sn-glycero-3-phosphocholine (DPPC) were carried out by means of the Langmuir monolayer technique using subphases containing chitosan (Ch), titanium (IV) oxide $\left(\mathrm{TiO}_{2}\right)$, hyaluronic acid (HA) or mixture of them. The aim was to determine the effect of individual components of subphase and their respective combinations on behavior of the DPPC membrane. The systems were tested at room temperature $\left(20^{\circ} \mathrm{C}\right)$ and at a natural $\mathrm{pH}$ of about 4.8 , which was close to the $\mathrm{pH}$ of the human skin (4.7-5.6). The surface pressure-area per molecule $(\pi-\mathrm{A})$ isotherms were obtained. Their analysis showed that all substances studied affected the phospholipid membrane which was revealed in the changes of mean molecular area, compression modulus and pressure of the liquidexpanded/liquid-condensed (LE/LC) phase transition. The results were discussed in terms of the nature and strength of mutual interactions. The more profound effect was found at low surface pressures at which the monolayers occurred in more expanded state. However, at the surface pressure corresponding to that of biological membranes, systems had very similar parameters compared to model DPPC isotherm.
\end{abstract}

Keywords DPPC isotherm · Langmuir technique · Chitosan · Titanium dioxide $\cdot$ Hyaluronic acid

\section{Introduction}

Chitosan $(\mathrm{Ch})$ is a biopolymer that has recently enjoyed a lot of popularity. This is due to a number of its interesting properties, resulting from its structure. Chemically, it is a polysaccharide composed of two units: 2-acetamido-2-deoxy$\beta$-D-glucopyranose and 2-amino-2-deoxy- $\beta$-D-pyranose, containing in the structure amine and hydroxyl moieties. The amine groups make $\mathrm{Ch}$ a cationic polyelectrolyte, and along with the hydroxyl groups, involved in the adsorption processes and other interactions. Due to its bioactivity and biodegradability $\mathrm{Ch}$ is popular among pharmaceutical, medical and cosmetic concerns. It is used primarily as a support for the supply of drugs and proteins (Moradi et al. 2019), biosensors (Zhang et al. 2018), nanofibers (scaffolds in tissue engineering) (Rijal et al. 2018; Bhowmick et al. 2018). In the area of life science, titanium dioxide $\left(\mathrm{TiO}_{2}\right)$ is also often found, which is generally associated with its role as

Agata Ładniak

agata.gozdecka@poczta.umcs.lublin.pl

1 Department of Interfacial Phenomena, Faculty of Chemistry, Maria Curie-Skłodowska University, 20-031 Lublin, Poland natural, physical UV filter or drug filler. It has been proven that chitosan can form stable bonds with $\mathrm{TiO}_{2}$ (Hasmath Farzana and Meenakshi 2014; Raut et al. 2016; Gozdecka and Wiącek 2018) and resulting product shows synergy of their properties. Moreover, some studies confirm that both titanium(IV) oxide and chitosan have antimicrobial (antibacterial, antifungal) properties (Krajewska et al. 2011; Uranga et al. 2019; Desai and Kowshik 2009; Scuderi et al. 2016; Jesline et al. 2015; Verdier et al. 2014; Bonnet et al. 2015) and also show non-toxicity (Khojasteh et al. 2016; Ji et al. 2016; Reis Éde et al. 2016).

The biocompatibility of the $\mathrm{Ch} / \mathrm{TiO}_{2}$ system can be increased by the presence of hyaluronic acid (HA) - the dermis component. In an adult human body it is about $15 \mathrm{~g}$ and more than half (56\%) of the body fluids resources is located in the skin. However, the content of hyaluronic acid in the skin is not constant. Its level increases during inflammatory processes, during rapid proliferation, regeneration and in tissue repair processes (Raszeja-Kotelba et al. 2002; Lemperle et al. 2003; Laurent and Fraser 1992).

HA is a linear polymer composed of disaccharide units consisting of the acids: $\beta$-D-glucuronic acid and $N$-acetyl$\beta$-D-glucosamine (in the ratio $1: 1$ ). In human skin, it is a 
component of the intercellular matrix of the dermis, however, it does not itself create a typical proteoglycan (by the inability to form a covalent bond with proteins). Despite this, in the extracellular space, it interacts non-covalently with many different molecules, constituting an axis for the growth of other glucosaminoglycans (Raszeja-Kotelba et al. 2002). HA chains are not amenable to any modifications (including epimerization), hence in the system (in body fluids), it may differ only in the length of the chain, which determines the size of the molecule. The negatively charged polymer chains have the ability to retain water and associate with the remaining components of the connective tissue. Water is bound in the polysaccharide network, composed of hyaluronic acid and proteoglycans, which results in high tissue resistance to water flow (Laurent and Fraser 1992). Owing to these properties, hyaluronic acid is responsible for the integrity of the intercellular tissue substance, gives it elasticity and flexibility (Kroma et al. 2012). The polysaccharide network of high molecular weight HA also binds low molecular ions, fulfills the function of osmotic buffer and has the ability to spherical exclusion of various molecules depending on their size, which is important in protecting tissues against penetration of bacteria, fungi and viruses (Laurent and Fraser 1992). In addition, it participates in the sequestration of reactive oxygen species, which is why it is included in compounds called scavengers of free radicals and detoxifying compounds (Taylor and Gallo 2006). In dermatology, among others in the treatment of burns and scars, and for replenishing the loss of subcutaneous tissue, HA is used. In addition, it reduces pruritus in the hypertrophic scar, and after removal it prevents its re-emergence.

The use of natural polymers, including chitosan and hyaluronic acid, allows obtaining materials with properties similar to those of the extracellular matrix. The advantage of this type of materials is their additional biocompatibility, lack of toxicity and low propensity to induce allergic reactions and a relatively low price. They often play a very specific role in the process of skin tissue reconstruction, inter alia, being the place of cell adhesion. Among commercially available natural polymers, chitosan is the only polymer exhibiting antimicrobial activity. However, despite the wide spectrum of activity, it does not negatively affect the growth of damaged tissue cells.

This article has been devoted to the determination of the influence of individual components as well as the created multiple system on a model biological membrane, formed by phospholipid DPPC using the Langmuir monolayer technique.

DPPC is the main component of many lung surfactants. It consists of two palmitic acids attached to the main group of phosphatidylcholine. It is a zwitterionic because of the presence of negative charge on the phosphate group and the positive charge on the quaternary ammonium group (Jurak and Wiącek 2017). Its structure allows forming monomolecular layers at the liquid-gas interface in the Langmuir trough which mimic membranes in living organisms. It seemed interesting to study how individual components of subphases influence on the model DPPC membrane behavior, thus the interactions in physiologically active systems. It was found that composition of the subphase affects the DPPC monolayer properties. As a consequence of mutual interactions there occur changes in mean molecular area, packing and ordering, and pressure of phase transition. However, these do not interfere with the structure at a pressure corresponding to that of biological membrane $(35 \mathrm{mN} / \mathrm{m})$, leaving it homogenous, compact and sufficiently rigid. This work is part of the research to characterize the combination of titanium dioxide with chitosan and hyaluronic acid. It has been recently published (Hasmath Farzana and Meenakshi 2014; Raut et al. 2016; Gozdecka and Wiacek 2018) that these substances have a stable/durable combination, and the synergy of certain properties has been confirmed.

\section{Experimental}

\subsection{Materials}

Titanium dioxide - $\mathrm{TiO}_{2} \mathrm{P}-25$ Evonik (early Degussa), finegrained, purified by procedure described in the next section (see Sample preparation), chitosan-(Acrōs Organics, ACRS34905) molecular weight 100,000-300,000 (applied without purification), acetic acid-Avantor Performance Materials, with a purity of $99.9 \%$ (as the solvent for chitosan and the environment for other systems) and hyaluronic acid-a commercial $1 \%$ solution stored at $5{ }^{\circ} \mathrm{C}$, was used to prepare the subphase for DPPC-1,2-dipalmitoyl-sn-glycero-3-phosphocholine, Sigma, with a purity $>99 \%$ (stored at $-20{ }^{\circ} \mathrm{C}$ ) dissolved in chloroform-Avantor Performance Materials, with a purity of $98.5 \%$.

\subsection{Methods: compression isotherms}

The surface pressure-molecular area $(\pi-\mathrm{A})$ isotherms were registered for monolayers obtained in a computer-controlled KSV standard-trough (KSV Instruments Ltd., Finland). The apparatus consists of trough, two movable barriers and a Wilhelmy plate-serving as a pressure sensor. The whole system is placed on an anti-vibration table. The temperature during the tests was $20 \pm 1^{\circ} \mathrm{C}$, maintained by a thermostated circulating water system.

After precise cleaning and preparing the test trough was filled with subphase. Next chloroform solution of DPPC was applied dropwise on it. Following evaporation of the solvent (typically about $10 \mathrm{~min}$ ), the compression of the phospholipid monolayer began. Compression occurred through the 
movement of barriers towards the center of the trough at a constant, pre-set speed of $10 \mathrm{~mm} / \mathrm{min}$.

\subsection{Sample preparation}

\subsubsection{Purification of $\mathrm{TiO}_{2}$}

Commercial $\mathrm{TiO}_{2}$ was subjected to further purification according to the procedure described by Preočanin and Kallay (2006). The suspension of $\mathrm{TiO}_{2}$ in water was sonificated for $30 \mathrm{~min}$ and the $\mathrm{pH}$ was adjusted by the addition of $\mathrm{NaOH}$ solution $(0.1 \mathrm{M})$ to obtain neutral $\mathrm{pH}$ close to the isoelectric point. The purified powder of $\mathrm{TiO}_{2}$ was dried at $100{ }^{\circ} \mathrm{C}$. After that, it was ground using a mortar and was stored in a desiccator. More details are presented in our previous papers (Wiącek et al. 2014, 2018; Gozdecka and Wiącek 2017, 2018).

\subsubsection{Subphase preparation}

Eight different subphases for the DPPC monolayer were prepared:

- acetic acid (AA) $0.1 \%$-AA,

- chitosan $(\mathrm{Ch})(0.1 \mathrm{mg} / \mathrm{mL})$ in acetic acid $(0.1 \%)$ - AA/ $\mathrm{Ch}$,

- hyaluronic acid (HA) in acetic acid $(0.1 \%)(\mathrm{v} / \mathrm{v}$ $0.5 \mathrm{~mL} / \mathrm{L})-\mathrm{AA} / \mathrm{HA}$,

- chitosan $(0.1 \mathrm{mg} / \mathrm{mL})$ in acetic acid $(0.1 \%)$ with the addition of hyaluronic acid (v/v $0.5 \mathrm{~mL} / \mathrm{L})-\mathrm{AA} / \mathrm{Ch} / \mathrm{HA}$,

- titanium dioxide $\left(\mathrm{TiO}_{2}\right)$ in acetic acid $(0.1 \%) 1.2 \mathrm{mg} /$ $\mathrm{mL}-\mathrm{AA} / \mathrm{TiO}_{2}$,

- titanium dioxide $(1.2 \mathrm{mg} / \mathrm{mL})$ with chitosan $(0.1 \mathrm{mg} / \mathrm{mL})$ in acetic acid $(0.1 \%)-\mathrm{AA} / \mathrm{Ch} / \mathrm{TiO}_{2}$,

- titanium dioxide in acetic acid $(1.2 \mathrm{mg} / \mathrm{mL})$ with the addition of hyaluronic acid (v/v $0.5 \mathrm{~mL} / \mathrm{L})-\mathrm{AA} / \mathrm{TiO}_{2} /$ HA,

- titanium dioxide $(1.2 \mathrm{mg} / \mathrm{mL})$ with chitosan $(0.1 \mathrm{mg} / \mathrm{mL})$ in acetic acid $(0.1 \%)$ with the addition of hyaluronic acid (v/v $0.5 \mathrm{~mL} / \mathrm{L})-\mathrm{AA} / \mathrm{Ch} / \mathrm{TiO}_{2} / \mathrm{HA}$.

For the preparation of stock acetic acid solution (which was the environment and the solvent for the other systems), water purified by the Milli-Q Plus 185 system from Millipore (USA) (conductivity $18.2 \mathrm{M} \Omega \mathrm{cm}$ ) was used. The remaining samples were made by measuring/releasing and combining the appropriate amounts of components.

\subsubsection{DPPC solution}

A DPPC phospholipid at a concentration of $1 \mathrm{mg} / \mathrm{ml}$ was used to prepare the model biological membrane. The solution was prepared directly before the measurements, and was stored at $-20^{\circ} \mathrm{C}$, no longer than 2 days. As the solvent for the DPPC, chloroform with purity $\geq 98.5 \%$ from Avantor Performance Materials was used.

\subsection{Characterization of $\mathrm{TiO}_{2}-\mathrm{P} 25$ particles, $\mathrm{Ch}$ and $\mathrm{Ch} / \mathrm{TiO}_{2}$ composite}

Characterization of $\mathrm{TiO}_{2}$ particles, $\mathrm{Ch}$ and $\mathrm{Ch} / \mathrm{TiO}_{2}$ composite was made on the basis of particle diameter studies-by dynamic light scattering, the presence of atoms and moieties, FTIR-ATR and XPS methods, which have already been described in our previous papers (Wiącek et al. 2014; Gozdecka and Wiacek 2017, 2018). It is suggested that the chitosan adsorbs onto the oxide particles, thereby significantly increasing their stability, by increasing the repulsive forces between them, consequently leading to the formation of the composite.

\section{Results}

\subsection{Surface pressure-area $(\pi-A)$ isotherms}

As a result of the compression of the phospholipid monolayer formed, isotherms of surface pressure as a function of the area per molecule in monolayer are obtained, in brief as $\pi-\mathrm{A}$ isotherms. Surface pressure defined as the difference between water surface tension and surface tension in the presence of monolayer was measured by the Wilhelmy method. Compression isotherms are characterized by particular regions that depict the state of the DPPC monolayer: gas (G), decompressed liquid (LE), LE-LC phase transition, and condensed LC.

The physical state of the monolayer, which changes during compression, is influenced by the interactions between the molecules in the surface layer, whose force and range change due to approaching the molecules to each other. Particular orientation and packing of molecules on the subphase surface correspond to the specific states. The highly decompressed monolayers formed after application of the solution are in the gaseous state. As the molecules approaching each other in the monolayer the interactions between them are getting stronger, causing an increase in surface pressure, suggesting the transition from the gas phase (G) to the decompressed liquid (LE). Further compression leads to a phase transition from decompressed liquid state (LE) to condensed liquid (LC). This transition is manifested on isotherms usually as a region with a constant pressure (plateau), and is called as the first order phase transition $\left(\pi_{\mathrm{pt}}\right)$ (Jurak and Chibowski 2010; Jurak et al. 2016; Jurak and Miñones 2016). Moreover, based on the compression isotherms $(\pi-\mathrm{A})$, the following parameters were determined: 
lift off area $\left(\mathrm{A}_{\mathrm{o}}\right)$, limit area $\left(\mathrm{A}_{\text {lim }}\right)$, compression modulus $\left(\mathrm{C}_{\mathrm{s}}^{-1}\right)$. Parameter $\mathrm{A}_{0}$ defines the value of the area at which the transition from the gas phase to the expanded liquid occurs, that is, when the isotherm begins to rise. On the other hand, limit area is a parameter that determines the area per molecule in a closely packed monolayer. It is determined by extrapolation of the linear part of the isotherm to zero value of surface pressure.

A useful parameter for full monolayers characterization is their compressibility, or its inverse, that is, the compression modulus, which assumes that the higher values the more condensed monolayer is. Compression modulus was calculated using numerical data of $\pi-\mathrm{A}$ isotherms, according to the following formula (Davies and Rideal 1963):

$C_{s}^{-1}=-A\left(\frac{d \pi}{d A}\right)_{n, T}$

where: $A$-area per molecule, $\pi$-surface pressure, $n-$ number of moles, $T$-temperature.

Very expanded monolayers are characterized by low $\mathrm{C}_{\mathrm{s}}^{-1}$ values $(12.5-50 \mathrm{mN} / \mathrm{m})$. However, during compression process the molecules in the monolayer are approaching and the interactions between them are getting stronger. For the liquid-condensed monolayers the $\mathrm{C}_{\mathrm{s}}{ }^{-1}$ values are within $100-250 \mathrm{mN} / \mathrm{m}$.

The LE-LC phase transition pressure seen as plateau in the course of the isotherm (Fig. 1) was precisely read from the graph of the dependency of the compression modulus as a function of the surface pressure (Fig. 2). The Fig. 2 shows a clear phase transition of the decompressed liquid-condensed liquid (LE-LC), which appears as a minimum in the course of the function, dividing the graph into two maxima

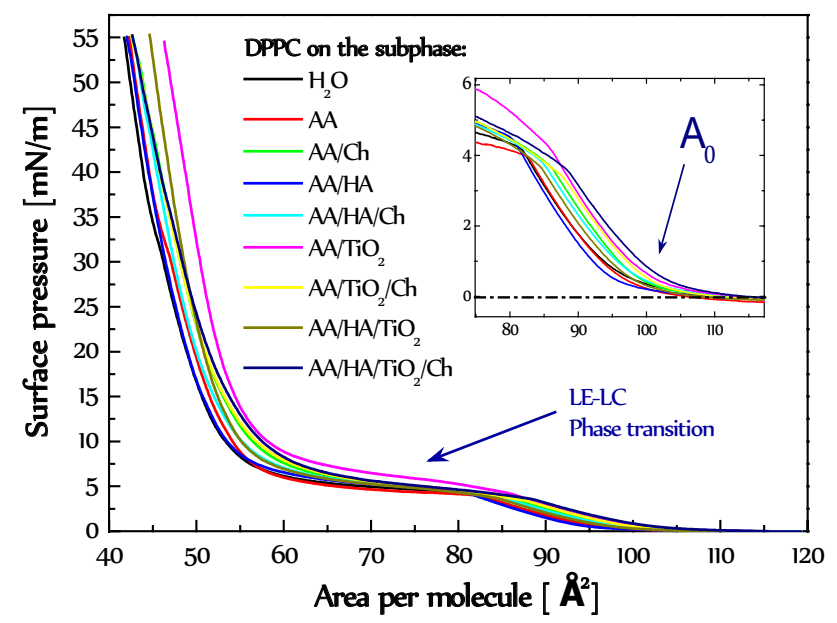

Fig. 1 Surface pressure-area $(\pi-\mathrm{A})$ isotherms of the DPPC monolayers registered on the different subphases at $20^{\circ} \mathrm{C}$, with the $\mathrm{A}_{0}$ parameter, where $\mathrm{A}_{0}$ - lift off area

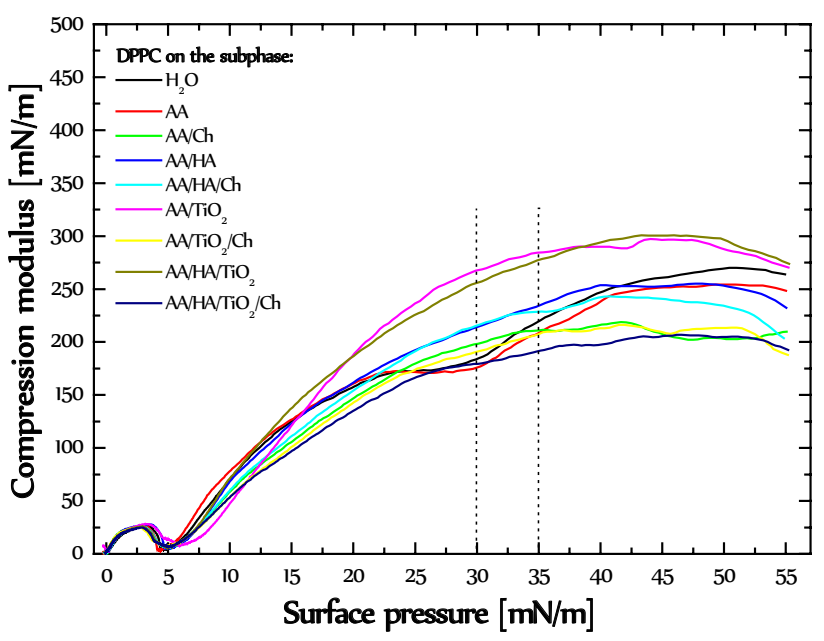

Fig. 2 Dependence of the compression modulus as a function of the surface pressure for the DPPC monolayer on all types of subphases

that correspond to the expanded liquid (LE) and the condensed liquid (LC), respectively.

During further compression an increase in surface pressure and the modulus was observed in the order of $100-250 \mathrm{mN} / \mathrm{m}$, characteristic for the monolayer in the state of the condensed liquid (Guzmán et al. 2017; Krajewska et al. 2011; Pavinatto et al. 2007, 2010; Cámara et al. 2016). Within this phase there are already strong intermolecular interactions, and that is why in monolayer there are areas with significant ordering and packing of molecules.

\subsection{DPPC monolayer on water and AA}

With regard to the DPPC isotherm obtained on the water, the presence of AA in the subphase caused a slight shift (by about $1.2 \mathrm{mN} / \mathrm{m}$ ) of the initial part of isotherm

Table 1 Parameter: $\mathrm{A}_{0}$ (lift off area), $\mathrm{A}_{\mathrm{lim}}$ (limit area) and $\pi_{\mathrm{pf}}$ (LE-LC phase transition) values for the DPPC monolayer on the different subphases

\begin{tabular}{|c|c|c|c|}
\hline \multirow[t]{2}{*}{ Subphase } & \multicolumn{3}{|l|}{ DPPC } \\
\hline & $\overline{\mathrm{A}_{0}\left[\AA^{2} / \text { molecule }\right]}$ & $\pi_{\mathrm{pf}}[\mathrm{mN} / \mathrm{m}]$ & $\begin{array}{l}\mathrm{A}_{\lim }\left[\AA^{2} /\right. \\
\text { molecule }]\end{array}$ \\
\hline $\mathrm{H}_{2} \mathrm{O}$ & 97.9 & 4.5 & 52.8 \\
\hline $\mathrm{AA}$ & 96.7 & 4.3 & 53.9 \\
\hline $\mathrm{AA} / \mathrm{Ch}$ & 99.1 & 4.5 & 55.7 \\
\hline $\mathrm{AA} / \mathrm{HA}$ & 93.5 & 5.0 & 51.0 \\
\hline $\mathrm{AA} / \mathrm{HA} / \mathrm{Ch}$ & 99.4 & 5.5 & 53.6 \\
\hline $\mathrm{AA} / \mathrm{TiO}_{2}$ & 101.3 & 5.8 & 55.8 \\
\hline $\mathrm{AA} / \mathrm{TiO}_{2} / \mathrm{Ch}$ & 100.4 & 4.5 & 55.0 \\
\hline $\mathrm{AA} / \mathrm{HA} / \mathrm{TiO}_{2}$ & 97.9 & 5.2 & 53.7 \\
\hline $\mathrm{AA} / \mathrm{HA} / \mathrm{TiO}_{2} / \mathrm{Ch}$ & 102.8 & 5.5 & 55.6 \\
\hline
\end{tabular}


towards the lower area per molecule values (see parameter $\mathrm{A}_{0}$-Table 1). By that act it adopted a lower value of the LE-LC phase transition pressure in the range of 100-60 $\AA^{2}$. However, in the range of 55-40 $\AA^{2}$, it assumes higher area values for appropriate pressures compared to the isotherm obtained for water, while maintaining a proportional slope of the curve. Therefore, for the AA system a higher value of $\mathrm{A}_{\lim }-53.9 \AA^{2}\left(\right.$ for $\mathrm{H}_{2} \mathrm{O}-52.8 \AA^{2}$ ) was obtained, as well as lower values of the compression modulus at high pressures. This suggests strengthening of the interactions in monolayer at low surface pressures and increasing flexibility at high $\pi$ values, which may indicate a strong interactions between DPPC and acetic acid molecules.

\subsection{DPPC monolayer on AA/Ch and AA/HA}

The addition of $\mathrm{Ch}$ into the system resulted in shifting the initial stage of the isotherm (by about $1.2 \mathrm{mN} / \mathrm{m}$ ) towards higher area per molecule values, as well as higher pressures, in relation to the isotherm recorded on the water subphase. As compared to AA, acceleration of the transition of DPPC from the gas to the liquidexpanded state $\left(\mathrm{A}_{0}-99.1 \AA^{2}\right)$, simultaneously delayed the LE-LC transition, which required a slightly higher pressure $\left(\pi_{\mathrm{pt}}=4.5 \mathrm{mN} / \mathrm{m}\right)$. The addition of Ch caused a stronger shift of the linear part of the isotherm into the right-hand side of the graph, which confirms the statement of Cámara et al. (2016) about the existence of strong electrostatic interactions between the polymer and the phospholipid.

While, in the case of the system with hyaluronic acid system (AA/HA), the greatest changes were observed in the initial stage of the isotherm, where the gas-expanded liquid phase transition delayed $\left(\mathrm{A}_{0}-93.5 \AA^{2}\right)$, resulting in almost the largest isotherm displacement, relative to an isotherm registered for water subphase. Also the LE-LC transition required other conditions, i.e. higher pressure $\pi_{\mathrm{pf}}$ equals $5.0 \mathrm{mN} / \mathrm{m}$. This means that HA hinders verticalization of the DPPC molecules.

Ultimately however, the isotherm showed the smallest shift at a pressure in the range of $10-30 \mathrm{mN} / \mathrm{m}$ (in comparison with the AA/Ch and AA systems). Above the pressure of $30 \mathrm{mN} / \mathrm{m}$ there are slight fluctuations in the course of the isotherm, consequently higher levels of the compressibility modulus, and above $\pi=40 \mathrm{mN} / \mathrm{m}$-lower levels $\mathrm{C}_{\mathrm{S}}^{-1}$ (Fig. 2), are registered.

The combination of $\mathrm{Ch}$ with $\mathrm{HA}$ in the subphase caused changes in the course of the isotherm to move towards larger molecular areas. However, at the pressure above the first order phase transition $\left(\pi_{\mathrm{pt}}=5.5 \mathrm{mN} / \mathrm{m}\right)$, isotherm took the intermediate $\pi$ and A values situated between the AA/Ch and AA/HA isotherms. Finally however, above value $\pi=45 \mathrm{mN} / \mathrm{m}$, it approached to the first one isotherm. This can suggest that mainly $\mathrm{Ch}$ molecules interact with the monolayer (and stay in it) at higher pressure values.

\subsection{DPPC monolayer on the subphases with $\mathrm{TiO}_{2}$}

In the case of earlier depicted systems, the changes were small, but drastic changes were observed for the $\mathrm{TiO}_{2}$ containing systems. The presence of oxide accelerated the G-LE phase transition, occurred as far back at $\mathrm{A}_{0}=101.3 \AA^{2}$, also significantly delayed the transition of LE-LC, required the highest pressure $\pi_{\mathrm{pt}}=5.8 \mathrm{mN} / \mathrm{m}$ (Table 1 ) in comparison with all other subphases. In reference to the isotherm registered for water, the full isotherm obtained on the $\mathrm{AA} / \mathrm{TiO}_{2}$ subphase was located in the area of higher surface pressures. Simultaneously the highest packing revealing in the high values of the compression modulus can suggest the penetration of $\mathrm{TiO}_{2}$ particles between DPPC molecules.

Whereas, the mixture of $\mathrm{Ch}$ with $\mathrm{TiO}_{2}$ showed how remarkable can be the effect of $\mathrm{Ch}$ on physico-chemical properties of this composite, because the isotherm took on almost the same shape as that obtained for the alone biopolymer (AA/Ch). The difference in the course of the isotherm was visible only at low pressure values. The isotherm began to rise at the surface value of the intermediate between AA/ Ch systems $\left(\mathrm{A}_{0}=99.1 \AA^{2}\right)$ and $\mathrm{AA} / \mathrm{TiO}_{2}\left(\mathrm{~A}_{0}=101.3 \AA^{2}\right)$, namely-100.4 $\AA^{2}$. This can suggest that the long $\mathrm{Ch}$ molecules surround the $\mathrm{TiO}_{2}$ particles, hindering the inorganic substance from contacting the monolayer, thereby causing smaller changes throughout the isotherm course. This statement is also confirmed by slightly smaller compression modulus values, but more similar to those obtained for AA/ Ch subphase, than for the lower modulus values by about $100 \mathrm{mN} / \mathrm{m}$ in the case of the $\mathrm{AA} / \mathrm{TiO}_{2}$ system (see Table 2).

For the $\mathrm{AA} / \mathrm{HA} / \mathrm{TiO}_{2}$ subphase the isotherm begins to rise, at the intermediate value for those obtained for AA/ $\mathrm{HA}\left(\mathrm{A}_{0}=93.5 \AA^{2}\right)$ and $\mathrm{AA} / \mathrm{TiO}_{2}\left(\mathrm{~A}_{0}=101.3 \AA^{2}\right)$ respectively, specifically $97.9 \AA^{2}$. And this course also maintains throughout the duration of compression process. Only in the area of 80-65 $\AA^{2}$, i.e. this is in the range of the first order phase transition, it approached to the isotherm registered for the monolayer on the subphase AA/HA. For the example of this connection, it is perfectly seen how one component can reduce the effect of the other, because intermediate values for all the investigated parameters were obtained between those for pure components. This may suggest the occurrence of component competition in the interactions with DPPC molecules.

Analyzing the isotherm for the most complex system containing all of the listed components, it can be seen that the presence of $\mathrm{TiO}_{2}$ had the greatest effect on the isotherm 
Table 2 Compression modulus for the decompressed liquid (LE) and the condensed liquid (LC) states and additionally at 30 and $35 \mathrm{mN} / \mathrm{m}$ pressures

\begin{tabular}{|c|c|c|c|c|c|c|}
\hline \multirow[t]{3}{*}{ Subphase } & \multicolumn{6}{|c|}{ DPPC } \\
\hline & \multicolumn{2}{|c|}{$\begin{array}{l}\mathrm{C}_{\mathrm{S}}^{-1} \max . \\
{[\mathrm{mN} / \mathrm{m}]}\end{array}$} & \multicolumn{2}{|l|}{$\pi=30 \mathrm{mN} / \mathrm{m}$} & \multicolumn{2}{|l|}{$\pi=35 \mathrm{mN} / \mathrm{m}$} \\
\hline & LE & $\mathrm{LC}$ & $\mathrm{C}_{\mathrm{S}}^{-1}[\mathrm{mN} / \mathrm{m}]$ & A $\left[\AA^{2} /\right.$ molecule $]$ & $\mathrm{C}_{\mathrm{S}}^{-1}[\mathrm{mN} / \mathrm{m}]$ & $\mathrm{A}\left[\AA^{2} /\right.$ molecule $]$ \\
\hline $\mathrm{H}_{2} \mathrm{O}$ & 34.8 & 332.7 & 189.2 & 46.2 & 186.8 & 44.9 \\
\hline AA & 32.8 & 324.6 & 169.6 & 47.1 & 183.5 & 45.6 \\
\hline $\mathrm{AA} / \mathrm{Ch}$ & 31.5 & 276.2 & 211.2 & 48.1 & 202.5 & 47.0 \\
\hline AA/HA & 32.7 & 314.3 & 215.9 & 46.5 & 232.1 & 45.5 \\
\hline $\mathrm{AA} / \mathrm{HA} / \mathrm{Ch}$ & 30.8 & 315.6 & 231.4 & 47.4 & 242.3 & 46.4 \\
\hline $\mathrm{AA} / \mathrm{TiO}_{2}$ & 35.3 & 356.0 & 299.4 & 50.4 & 292.7 & 49.5 \\
\hline $\mathrm{AA} / \mathrm{TiO}_{2} / \mathrm{Ch}$ & 32.0 & 269.5 & 199.3 & 48.2 & 201.2 & 46.9 \\
\hline $\mathrm{AA} / \mathrm{HA} / \mathrm{TiO}_{2}$ & 33.0 & 354.5 & 247.2 & 48.6 & 288.0 & 47.7 \\
\hline $\mathrm{AA} / \mathrm{HA} / \mathrm{TiO}_{2} / \mathrm{Ch}$ & 31.8 & 256.8 & 196.0 & 48.4 & 186.3 & 47.1 \\
\hline
\end{tabular}

course at low surface pressures, transferring the initial part of the isotherm to higher molecular areas $\left(\mathrm{A}_{0}=102.8 \AA^{2}\right)$. The addition of HA had an effect on increasing the pressure value for LE-LC transition; whereas Ch effect was dominated in monolayers at high surface pressure values, which may indicate its penetration and staying in it, even when monolayer is closely packed-causing its elasticity to increase.

Summary, as can be seen in Fig. 1 and Table 1 , the $\mathrm{A}_{0}$ values increase with the addition of further components to the subphase, which indicates that the $\mathrm{Ch}$ and $\mathrm{TiO}_{2}$ get between the DPPC molecules weakening the attraction forces between the phospholipid molecules. Only the use of AA and AA with the addition of HA has the opposite effect, that is, it enhances the attraction forces between the DPPC molecules probably as an effect of the high viscosity changes. The biggest shift occurred in the case of the AA/ $\mathrm{HA} / \mathrm{TiO}_{2} / \mathrm{Ch}$ system (difference $4.9 \mathrm{mN} / \mathrm{m}$, in relation to water), while the smallest changes took place in the presence of the $\mathrm{AA} / \mathrm{HA} / \mathrm{TiO}_{2}$ system (difference $0.1 \mathrm{mN} / \mathrm{m}$ ).

As can be seen in Table 1-limit area per molecule in monolayer grows with increasing amounts of components in the subphase (except AA/HA), suggesting that even at high compression, subphase components noticeably affect the monolayer organization (structure).

In the Table 2 and Fig. 2 we have distinguished two pressures of 30 and $35 \mathrm{mN} / \mathrm{m}$ because these values correspond to the pressure of the biological membranes. In this range of pressures the DPPC monolayer formed a compact homogeneous structure, which was sufficiently rigid. The higher value of the compression modulus proves greater condensation of the monolayer.

\section{Discussion}

In order to determine the interactions between chitosan, titanium dioxide, hyaluronic acid and biomembranes, those of individual components with the DPPC phospholipid in the Langmuir monolayers as model membranes were investigated. Possible interactions were evaluated by monitoring the differences in the shape of the compression isotherms measured in the absence and presence of aforementioned substances in the subphase.

The individual components of the subphase did not disturb a course of the $\pi-\mathrm{A}$ isotherms, to a greater extent. At low surface pressures (i.e., at large areas per molecule) the elasticity of the DPPC monolayer is greater in the presence of $\mathrm{Ch}, \mathrm{TiO}_{2}$, or HA. However, all isotherms retain the flatness typical for the first order LE-LC transition. The isotherms at this pressure show no significant reduction in elasticity. This is indicated by the value of the phase transition pressure, which proves that the composition of the subphase does not result in the disappearance of the LE-LC phase transition-characteristic for DPPC phospholipid, only affects the change in pressure value at which it occurs.

Considering the addition of $\mathrm{TiO}_{2}$ to individual systems, it can be seen that in each case it causes the shift of the $\pi-\mathrm{A}$ isotherms to the region of larger area per molecule values. This suggests a very strong effect of this component on the properties of particular substances in subphases. Such behaviour was also confirmed by other authors (Guzmán et al. 2017). This is the result of penetration of $\mathrm{TiO}_{2}$ particles into a single layer of DPPC molecules and consequently a change in monolayer morphology. Considering the charge present on the surface: positive for $\mathrm{TiO}_{2}$ and negative charge of the phosphate group in the amphoteric, hydrophilic "head" of the phospholipid, it was concluded that the incorporation of $\mathrm{TiO}_{2}$ into the monolayer is mediated by electrostatic interactions. However, Guzmán et al. (2017) did not notice any clear relationships between the scale of 
the isotherm shift and the concentration of nanoparticles in the subphase, while concluding that the nanoparticles are strongly embedded in a single layer, due to the presence of other interactions, e.g. hydrogen bonds. The existence of strong interactions between subphase components and the phospholipid film is evidenced by higher values of compression modulus suggesting that monolayers create a packed and stiffer structure. Systems containing $\mathrm{TiO}_{2}$ show high $\mathrm{C}_{\mathrm{S}}{ }^{-1}$ values; only after mixing combination with $\mathrm{Ch}-$ lower, which is probably the result of the composite formation, where the biopolymer forms a coating on the oxide particles.

Chitosan alone (AA/Ch system) causes the curves shift to the right on the graph compared to the $\mathrm{H}_{2} \mathrm{O}$, AA subphase respectively, which means that monolayers have been extended and that the $\mathrm{Ch}$ addition to the subphase exerts a membrane interference effect. The similar observations were noted by Krajewska et al. (2011) and Pavinatto et al. (2007). In addition, $\mathrm{Ch}$ enhances this shift in other tested mixtures (except for the $\mathrm{AA} / \mathrm{TiO}_{2} / \mathrm{Ch}$ system, where a smaller shift was recorded than for the $\mathrm{AA} / \mathrm{TiO}_{2}$ system but larger than for the AA/Ch). The low values of compression modules at high surface pressure values may suggest that chitosan interacts with DPPC via weak electrostatic interactions. However, the fact that the $\mathrm{AA} / \mathrm{Ch}$ and $\mathrm{AA} / \mathrm{Ch} / \mathrm{TiO}_{2}$ systems showed similar parameters proves the existence of additional relationships. The research carried out by Pavinatto et al. (2010) and Cámara et al. (2016) allowed to conclude that the effect of chitosan strongly depends either on its functional uncharged groups and/or on its specific conformation in the solution, which probably also occurs in our case.

The addition of HA only in the systems in which Ch was present caused the shift of the $\pi-\mathrm{A}$ isotherms towards larger molecular areas. In other cases (alone and in the presence of $\mathrm{TiO}_{2}$ ) it causes the opposite effect-it transfers the curves to the region of smaller area values. Analyzing the magnitude of changes the presence of HA and comparing the structure-similar to $\mathrm{Ch}$ molecules, we can conclude that the amide groups can be of great importance in the interactions with the phospholipid molecules. Ch causes opposite changes in the course of isotherms, as compared to those induced by HA, with much bigger number of amide groups. Degree of deacetylation (parameter determining the number of glucosamine groups relative to all glucosamine and $\mathrm{N}$-acetylglucosamine groups present in the polymer structure) of Ch used in our studies was about $82 \%$. Thus, both ammonium and hydroxyl groups can participate in interactions with the polar heads of DPPC molecules by electrostatic forces and/or hydrogen bonding. HA possesses protondonor and proton-acceptor groups which can take part in the acid-base interactions with DPPC but the electrostatic interactions are hardly possible.

The transfer of curves to the higher area values suggests that the individual components of the subphase get into the phospholipid layer (this is also confirmed by the increased values of $\mathrm{A}_{\mathrm{lim}}$ ) weakening the attraction forces between the phospholipid molecules. Growth of limit area parameter indicates, that even for high compression values, subphase components affect the monolayer structure. The higher $\mathrm{A}_{\mathrm{lim}}$ means that the more space in the entire monolayer falls on the one DPPC molecule, so that it is less packed and compact. This makes it difficult to take a vertical position by the DPPC molecules to form the condensed domains during the LE-LC phase transition, and finally a homogeneous film, that is reflected in the increased values of the LE-LC phase transition pressure values $\left(\pi_{\mathrm{ft}}\right)$.

\section{Conclusions}

The presence of $\mathrm{Ch}, \mathrm{TiO}_{2}$ and $\mathrm{HA}$ in the subphase noticeably influences on the DPPC membrane structure. This is evidenced in the modification of the packing degree defined by the values of the compressibility modulus and average area per molecule in the monolayer. It was obtained that the greatest changes of these parameters occur in the presence of $\mathrm{TiO}_{2}$ particles in the subphase. On the other hand at the pressure of 30 and $35 \mathrm{mN} / \mathrm{m}$ which correspond to that of the biological membranes, a $\mathrm{AA} / \mathrm{HA} / \mathrm{TiO}_{2} / \mathrm{Ch}$ system has a very similar parameters compared to model DPPC isotherm. The obtained results suggested that even at high compression, subphase components affect the monolayer organization (structure), increasing or reducing its flexibility. We hope that our studies can help in the scaling-up of $\mathrm{HA} / \mathrm{TiO}_{2} / \mathrm{Ch}$ systems applications of increased biocompatibility.

Acknowledgements Funding was provided by Ministry of Science and Higher Education of Poland (Grant No. BS-M-03-002-18-D-01).

\section{Compliance with ethical standards}

Conflict of interest The authors declare that they have no conflict of interest.

Open Access This article is distributed under the terms of the Creative Commons Attribution 4.0 International License (http://creativeco mmons.org/licenses/by/4.0/), which permits unrestricted use, distribution, and reproduction in any medium, provided you give appropriate credit to the original author(s) and the source, provide a link to the Creative Commons license, and indicate if changes were made.

\section{References}

Bhowmick, A., Banerjee, S.L., Pramanik, N., Jana, P., Mitra, T., Gnanamani, A., Das, M., Kundu, P.P.: Organically modified clay supported chitosan/hydroxyapatite-zinc oxide nanocomposites with enhanced mechanical and biological properties for the application 
in bone tissue engineering. Int. J. Biol. Macromol. 106, 11-19 (2018)

Bonnet, M., Massard, C., Veisseire, P., Camares, O., Awitor, K.O.: Environmental toxicity and antimicrobial efficiency of titanium dioxide nanoparticles in suspension. J. Biomater. Nanobiotechnol. 6(3), 213-224 (2015)

Cámara, C.I., Riva, J.S., Juárez, A.V., Yudi, L.M.: Interaction of chitosan and self-assembled distearoylphosphatidic acid molecules at liquid/liquid and air/water interfaces. Effect of temperature. J. Phys. Org. Chem. 29(11), 672-681 (2016)

Davies, J.T., Rideal, E.K.: Interfacial Phenomena, vol. 265 2nd ed. Academic Press, Cambridge (1963)

Desai, V.S., Kowshik, M.: Antimicrobial activity of titanium dioxide nanoparticles synthesized by sol-gel technique. Res. J. Microbiol. 4(3), 97-103 (2009)

Gozdecka, A., Wiącek, A.E.: Behaviour of $\mathrm{TiO}_{2} /$ chitosan dispersion as a function of solution pH. Prog. Chem. Appl. Chitin Deriv. 22, 27-41 (2017)

Gozdecka, A., Wiącek, A.E.: Effect of UV radiation and chitosan coating on the adsorption-photocatalytic activity of $\mathrm{TiO}_{2}$ particles. Mater. Sci. Eng. C 93, 582-594 (2018)

Guzmán, E., Santini, E., Ferrari, M., Liggieri, L., Ravera, F.: Effect of the incorporation of nanosized titanium dioxide on the interfacial properties of 1,2-dipalmitoyl-sn-glycerol-3-phosphocholine. Langmuir Monolayers 33(40), 10715-10725 (2017).

Hasmath Farzana, M., Meenakshi, S.: Synergistic effect of chitosan and titanium dioxide on the removal of toxic dyes by the photodegradation technique. Ind. Eng. Chem. Res. 53(1), 55-63 (2014)

Jesline, A., John, N.P., Narayanan, P.M., Vani, C., Murugan, S.: Antimicrobial activity of zinc and titanium dioxide nanoparticles against biofilm-producing methicillin-resistant Staphylococcus aureus. Appl. Nanosci. 5(2), 157-162 (2015)

Ji, D.l., Zhu, J., Ji, M., Leng, Y.: Enhanced photocatalytic reduction of $\mathrm{Cr}(\mathrm{VI})$ by manganese-doped anatase titanium dioxide. Res. Chem. Intermed. 42, 5413-5429 (2016)

Jurak, M., Chibowski, E.: Surface free energy and topography of mixed lipid layers on mica. Colloids Surf. B Biointerface 75(1), 165-174 (2010)

Jurak, M., Miñones, Jr.J.: Interactions of lauryl gallate with phospholipid components of biological membranes. Biochim. Biophys. Acta Biomembr. 1858(8), 1821-1832 (2016)

Jurak, M., Wiącek, A.E.: Wettability of hybrid chitosan/phospholipid coatings. Prog. Chem. Appl. Chitin Deriv. 22, 66-76 (2017)

Jurak, M., Wiącek, A.E., Terpiłowski, K.: Properties of PEEK-supported films of biological substances prepared by the LangmuirBlodgett technique. Colloids Surf. A Physicochem. Eng. Aspects 510, 263-274 (2016)

Khojasteh, H., Salavati-Niasari, M., Abbasi, A., Azizi, F., Enhessari, M.: Synthesis, characterization and photocatalytic activity of $\mathrm{PdO} /$ $\mathrm{TiO}_{2}$ and $\mathrm{Pd} / \mathrm{TiO}_{2}$ nanocomposites. J. Mater. Sci. Mater. Electron. 27(2), 1261-1269 (2016)

Krajewska, B., Wydro, P., Jańczyk, A.: Probing the modes of antibacterial activity of chitosan. Effects of $\mathrm{pH}$ and molecular weight on chitosan interactions with membrane lipids in Langmuir Films. Biomacromolecules 12, 4144-4152 (2011)

Kroma, A., Feliczak-Guzik, A., Nowak, I.: Zastosowanie glikozaminoglikanów w preparatach kosmetycznych. Chemik 66(2), 136139 (2012) (in Polish)

Laurent, T.C., Fraser, J.R.: Hyaluronan. FASEB J. 6, 2397-2404 (1992)

Lemperle, G., Morhenn, V., Charrier, U.: Human histology and persistence of various injectable filler substances for soft tissue augmentation. Aesthet. Plast. Surg. 27, 354-366 (2003)
Moradi, S., Hosseini, E., Abdoli, M., Khani, S., Shahlaei, M.: Comparative molecular dynamic simulation study on the use of chitosan for temperature stabilization of interferon $\alpha$ II. Carbohydr. Polym. 203, 52-59 (2019)

Pavinatto, F.J., Pavinatto, A., Caseli, L., dos Santos, D.S., Nobre, T.M., Zaniquelli, M.E.D., de Oliveira, O.N.: Interaction of chitosan with cell membrane models at the air-water interface. Biomacromolecules 8, 1633-1640 (2007)

Pavinatto, A., Pavinatto, F.J., Barros-Timmons, A., de Oliveira, O.N.: Electrostatic interactions are not sufficient to account for chitosan bioactivity. Appl. Mater. Interfaces 1(2), 246-251 (2010)

Preočanin, T., Kallay, N.: Point of zero charge and surface charge density of $\mathrm{TiO}_{2}$ in aqueous electrolyte solution as obtained by potentiometric mass titration. Croat. Chem. Acta 79, 95-106 (2006)

Raszeja-Kotelba, B., Neumann, E., Bowszyc, J.: Kwas hialuronowy i skóra. Polish J. Cosmetol. 1, 21-25 (2002) (in Polish)

Raut, A.V., Yada, H.M., Gnanamani, A., Pushpavanam, S., Pawar, S.H.: Synthesis and characterization of chitosan- $\mathrm{TiO}_{2}: \mathrm{Cu}$ nanocomposite and their enhanced antimicrobial activity with visible light. Colloids Surf. B Biointerfaces 148, 566-575 (2016)

Reis Éde, M., Rezende, A.A., Oliveira, P.F., Nicolella, H.D., Tavares, D.C., Silva, A.C., Dantas, N.O., Spanó, M.A.: Evaluation of titanium dioxide nanocrystal-induced genotoxicity by the cytokinesis-block micronucleus assay and the Drosophila wing spot test. Food Chem. Toxicol. 96, 309-319 (2016)

Rijal, N.P., Adhikari, U., Khanal, S., Pai, D., Sankar, J., Bhattarai, N.: Magnesium oxide-poly( $\varepsilon$-caprolactone)-chitosan-based composite nanofiber for tissue engineering applications. Mater. Sci. Eng. B 228, 18-27 (2018)

Scuderi, V., Buccheri, M.A., Impellizzeri, G., Di Mauro, A., Rappazzo, G., Bergum, K., Svensson, B.G., Privitera, V.: Photocatalytic and antibacterial properties of titanium dioxide flat film. Mater. Sci. Semicond. Process. 42(1), 32-35 (2016)

Taylor, K.R., Gallo, R.L.: Glycosaminoglycans and their proteoglycans: host associated molecular patterns for initiation and modulation of inflammation. FASEB J. 20, 9-22 (2006)

Uranga, J., Puertas, A.I., Etxabide, A., Dueñas, M.T., Guerrero, P., de la Caba, K.: Citric acid-incorporated fish gelatin/chitosan composite films. Food Hydrocoll. 86, 95-103 (2019)

Verdier, T., Coutand, M., Bertron, A., Roques, C.G.: Antibacterial activity of $\mathrm{TiO}_{2}$ photocatalyst alone or in coatings on E. coli: the influence of methodological aspects. Coatings 4(3), 670-686 (2014)

Wiącek, A.E., Anitowska, E., Delgado, A.V., Hołysz, L., Chibowski, E.: The electrokinetic and rheological behaviour of phosphatidylcholine-treated $\mathrm{TiO}_{2}$ suspensions. Colloids Surf. A 440, 110-115 (2014)

Wiącek, A.E., Gozdecka, A., Jurak, M.: Physicochemical characteristics of chitosan- $\mathrm{TiO}_{2}$ biomaterial. 1 . Stability and swelling properties. Ind. Eng. Chem. Res. 57, 1859-1870 (2018)

Zhang, Q., Qing, Y., Huang, X., Li, C., Xue, J.: Synthesis of singlewalled carbon nanotubes-chitosan nanocomposites for the development of an electrochemical biosensor for serum leptin detection. Mater. Lett. 211, 348-351 (2018)

Publisher's Note Springer Nature remains neutral with regard to jurisdictional claims in published maps and institutional affiliations. 